\title{
(息)
}

Citation:

Frost, NP (2019) Providing support and therapy for victims and survivors of Child Sexual Exploitation. Journal of Public Mental Health. ISSN 1746-5729 DOI: https://doi.org/10.1108/JPMH-07-2018-0051

Link to Leeds Beckett Repository record:

https://eprints.leedsbeckett.ac.uk/id/eprint/5523/

Document Version:

Article (Accepted Version)

The aim of the Leeds Beckett Repository is to provide open access to our research, as required by funder policies and permitted by publishers and copyright law.

The Leeds Beckett repository holds a wide range of publications, each of which has been checked for copyright and the relevant embargo period has been applied by the Research Services team.

We operate on a standard take-down policy. If you are the author or publisher of an output and you would like it removed from the repository, please contact us and we will investigate on a case-by-case basis.

Each thesis in the repository has been cleared where necessary by the author for third party copyright. If you would like a thesis to be removed from the repository or believe there is an issue with copyright, please contact us on openaccess@leedsbeckett.ac.uk and we will investigate on a case-by-case basis. 


\section{Providing support and therapy for victims and survivors of Child Sexual Exploitation.}

\section{Abstract \\ Purpose}

This article explores and analyses the public mental health challenges arising in the field of child sexual exploitation (CSE) utilising data gathered from frontline professionals.

Design / methodology / approach

The methods adopted include semi-structured, face-to-face individual interviews $(n=6)$ and focus groups (two groups with a total of eight participants, $n=8)$. All participants specialise in work with CSE-experienced young people.

Findings

Professionals report how they offer support, intervention and therapy to CSE experienced young people. Findings are outlined in relation to support, therapeutic interventions, multi-disciplinary working, 'what works?', and the challenges and issues faced in their professional roles. The respondents are confident in their trustbuilding and intervention skills but are concerned about a lack of sustained therapeutic support.

Research implications / limitations

The article reports briefly on a substantial amount of data. A further limitation is that there is a need to gather data directly from the perspective of young people.

Practice implications

The high quality of work undertaken and the need to further develop therapeutic work with the CSE experienced young people emerge from the findings.

Social implications

CSE is a high profile public health issue which attracts considerable public and political attention. The shortfall in sustained therapeutic support is highlighted.

Originality/ value 
The data gathered reflects the contemporary views of frontline professionals in a challenging and complex field of practice.

Key words: mental health, child sexual exploitation, therapy, support, professionals.

\section{Introduction}

Child sexual exploitation (CSE) is one of the many challenges facing contemporary health and child welfare professionals. Growing professional awareness, increased child trafficking and technological change have all contributed to both a rising awareness and incidence of CSE across the globe (Lefevre et al, 2017, Pearce, 2017). Whilst the immediate challenges of addressing disruption and intervention around CSE have improved in the U.K. (for a discussion of this see Hill, 2016, and Harris et al, 2017) since the publication of the influential Jay Report (2014), the longer terms challenges around the mental health and well-being of survivors remain a major shortfall in service provision (Warrington et al, 2017). This challenge has global public health implications as the extent and impact of all forms of sexual abuse, including CSE, have become more widely recognised (Pearce, 2017).

\section{CSE - history and policy.}

In his book, 'The Politics of Child Abuse' (1984), Parton demonstrated how our responses to child abuse change over time and he illustrates how professional practice relates to social and political factors. Never has this been more apparent than in the case of developments around CSE (Hallett, 2017). It is probably the case that CSE has existed throughout the centuries, however, we did not have the language or concepts to fully understand the nature and extent of what would today be identified as CSE. For example, the slave trade can now be seen as containing elements of child sexual exploitation (see Davis, 2002).

During the more recent history of CSE professionals did not have adequate knowledge to help them understand how young people, who were often described as 'runaways' and were seen as 'disruptive', were perhaps being sexually exploited. It now seems surprising that the term 'child prostitution' was utilised in professional circles and U.K. Government guidance until around 2005 (see for example 'Safeguarding Children involved in Child Prostitution', Department of Health, 2000). 
This brief historical perspective demonstrates how vital the deployment of concepts is: utilising the term 'child prostitution' led to professional responses which were not child-centered and focused on 'blaming' young people and their 'lifestyle choices'. The use of the term 'child sexual exploitation' has contributed to a better understanding of, and a better response to, this challenging social problem (Hill, 2016, Harris et al, 2017).

During 2017 the English Government issued guidance that argues that we need to place CSE in the wider context of child sexual abuse (CSA) as:

Child sexual exploitation is a form of child sexual abuse. It occurs where an individual or group takes advantage of an imbalance of power to coerce, manipulate or deceive a child or young person under the age of 18 into sexual activity (a) in exchange for something the victim needs or wants, and/or (b) for the financial advantage or increased status of the perpetrator or facilitator. The victim may have been sexually exploited even if the sexual activity appears consensual. (Department for Education, 2017, p.5)

This definition is utilised to inform this study and to explore the public mental health challenges that arise.

\section{CSE: what we know}

It is often argued that the professional response to CSE requires high quality, multiprofessional working (Jago et al, 2011, Hill, 2016). The importance of a co-ordinated, holistic response for young people is argued for by Ofsted in their report, 'Time to Listen':

'some children had too many professionals involved with them and a lack of co-ordination, together with assessments that did not consider all of the child's needs, meant that support for children was not meaningful to them' (Ofsted, 2016, p.3)

Our understanding of how to work effectively with CSE-experienced young people is at an early stage, as Hossain and colleagues argue, 'uncertainty persists regarding the best ways to address [victims and survivors] mental health needs' (2010, p. 2449). 
Lefevre et al argue that, in terms of mental health and related challenges:

'CSE is recognised as adversely affecting children's physical, mental and sexual health, educational achievements, social and economic contributions, and later parenting capacity, and increasing their risk of self-harming, drug and alcohol problems, and anti-social and criminal behaviours' (Lefevre et al, 2017, p. 2457)

The authors, drawing from a survey of a wide-range of professionals in the field, further argue that:

'Building the relationship often meant spending time with the children in a more relaxed and informal way, and engaging in mutual activities and talk which are not just about CSE. Interviewees spoke at length about going to cafes, going for walks, just chatting with young people about their everyday lives and 'not be looking at your watch" (Lefevre et al, 2017, p. 2459)

The wider social context of CSE is reflected upon by one young woman in a study by Beckett and colleagues as follows: 'I'm used to it...it's normal...it's wrong, but you get used to it...Welcome to our generation' (2013, p.43). According to this research, young people may have come to take the existence of sexual exploitation foregranted, as a feature of modern life (see Girl A (2013) for a moving personal account).

There do not seem to be many studies of the mental health impact of CSE, in particular, but there are international studies which explore the impact on survivors of trafficking, a process that shares many characteristics of CSE. An extensive U.S. study concludes that:

'Fifty-five per cent of participants met our criteria for high levels of depression symptoms, $48 \%$ met our criteria for high levels of anxiety symptoms, and $77 \%$ had possible PTSD.....many, but not all, of the trafficking-related exposures were more commonly reported among those participants with mental health symptoms...... Sexual violence during trafficking was associated with PTSD, and physical violence (being hit or kicked) during trafficking was positively associated with anxiety symptoms' (Hossain et al, 2010, p. 2445) 
Whereas there are some preventive programmes in place, and intervention has improved since the publication of the Jay Report (Hill, 2016, Harris et al, 2017), there remains a challenge in relation to the mental health of CSE victims and survivors: a challenge which is explored in the remainder of this article. As Warrington et al point out:

\begin{abstract}
'Some children experience delays of months or even years for access to therapeutic support post disclosure' $(2017$, p.9)
\end{abstract}

\title{
Design and Methods
}

The aim of this study was the gather and analyse the views and opinions of front-line professionals working in the CSE field. All professionals worked in multi-professional settings.

The methods included semi-structured, face-to-face individual interviews $(n=6)$ and focus groups (two groups with a total of eight participants, $n=8$ ). All participants work with CSE-experienced young people.

The teams and individuals were recruited using opportunity sampling: four multiprofessional teams were approached with two teams agreeing to be interviewed, 9 professionals were approached with 6 agreeing to be interviewed. Interviewees included social workers, project workers, police officers, health workers, support workers and coordinators: all working with young people at risk of, or experiencing, CSE. A semi-structured interview schedule was constructed, which was informed by issues the relevant literature.

Ethical approval was obtained from Leeds Beckett University. Ethical challenges related to anonymity, confidentiality and the potential identification of poor practice. The anonymity of all respondents is protected in the presentation of the data. In relation to confidentiality participants were advised not to use names, locations or other identifying material in their responses: all participations followed this advice. In relation to the identification of poor practice the Participant Information Sheet advised participants that if any serious safeguarding concerns emerged during the interviews then the researcher would be obliged to follow local safeguarding procedures. There was no need for this process to be instigated. 
All interviews were digitally recorded and transcribed. The data was coded and thematically analysed. The process was repeated to check for accuracy.

Findings: The views of professionals

Much of the contemporary knowledge of CSE and the subsequent therapeutic needs is a form of 'practice knowledge' which is situated with the small group of frontline professionals (see Eraut, 2002). The data is presented utilising the following themes that emerged from the thematic analysis: support needs of young people, therapeutic needs of young people, multi-disciplinary working, 'what works?', and issues and challenges.

\section{The support needs of young people}

The respondents identified supporting young people to develop their understanding and awareness of their situation as the starting point for their professional intervention. One of the focus group teams saw their role as educative and argued that they would build the relationship through information-giving:

'The first [challenge] we always think of is raising their awareness .... We offer them one-to-one support weekly, or more than that if they require it, and do work on on-line safety, grooming, sexual consent and so on' (Focus Group 1)

The professionals interviewed argued that the primary need of the young people was for relationships with professionals, which were sustainable, high quality and based on trust. Some placed the emphasis on trust, rather than the specific content of the work:

'The main issue is one of a 'trusting relationship' with one of the professionals: there is no right or wrong approach. It is about talking to somebody and that person not judging them' (CSE co-ordinator)

Building such relationships is challenging because trust has been systematically undermined by the grooming process: there is a 'risk young people often will not engage.... as they have been groomed not to engage' (CSE co-ordinator). Many respondents argued that the undermining of trust with parents and other relatives initially, and later with professionals, is core to the grooming process, and that this is 
a key feature of CSE. The impact of grooming, therefore, has specific forms in relation to CSE and has subsequent implications for mental health support.

The relationships with professionals, which build trust, can be organised around leisure and educational activities, rather than being specifically CSE focussed:

'We do things with the young people - go to cafes, swimming and so on - this allows you to build the trust, and then you can explore the CSE' (Young People's Support Officer)

According to the respondents CSE experienced young people have needs which can be met through education, awareness-raising, information-giving and activities: through this process 'trusted relationships' can develop which are perceived as being essential to the support process. This theme provides that starting point for our analysis: the grooming process has undermined trust in significant adults in the young person's life and, therefore, the first step in the support and therapeutic relationship is to build trust in the professionals working with the young person.

\section{Therapeutic needs of young people}

The interviews went on to explore longer terms needs once the CSE has been prevented or stopped, the initial steps have been taken to build trust, and to explore what the therapeutic implications are.

For the professionals CSE is central to the understanding of, and response to, to the mental health needs of young people:

'many of the young people have issues around self-harm, relationship problems and substance abuse and they need counselling as a result. But it is all linked with CSE' (Police Officer)

One respondent identified a return to educational settings as a priority, arguing that the young people had missed important educational opportunities:

'In the long-term is mainly about education. The young people may have missed a lot of education - and it is helpful to go back to education, if they can' (CSE co-ordinator) 
Again trust and being listened to emerged as a re-current theme:

'therapeutic input is about flexibility, building trust and being there for them. They need someone to go back to and is always there for them' (CSE social worker)

Many of the respondents felt that there was no one 'correct' therapeutic approach; they placed an emphasis on the specific relationship as the key protective and therapeutic tool. One of the respondents made this point as follows:

'There is no one correct therapy - just different therapies for different young people .... there is not one therapy that fits all - counselling and psychotherapy have a role, but we need integrative therapy, that takes into account the whole person and their needs. There are different timescales for everyone. Some programmes are 6-8 weeks, sometimes six months, or one to two years may be required. It is an indefinite process' (CSE co-ordinator)

This response summarises the 'personalised' approach which all the respondents favoured. This point was re-inforced by a health professional as follows:

'CBT is popular but I am not sure, as it is not always effective. We need a range of therapies that reflect what has happened to the young person'. (Health professional)

One of the challenges of dealing with CSE is in identifying the similarities to, and differences, from CSA. Many of the respondents had reflected on this and argued that there were significant differences.

'The main difference between young people who have experienced CSA and CSE is the grooming process. It drives a wedge between the young person and their family and that can make the young person difficult to engage with The child may have been using drugs and alcohol and that can sometimes add a dimension that makes it different from abuse within the family' (CSE co-ordinator)

There was concern about the long term impact if therapy is not available: 
'If there was more therapeutic support we would have more progression and they wouldn't go on to adulthood with such issues. Some have some who become sex workers as we haven't got to the deep-rooted reasons why young people do what they do' (Focus Group 1)

The focus on 'deep-rooted' causes was complex to pursue in practice and the focus on CSE was seen as artificial in some ways:

'CSE victims experience all sorts of issues, maybe domestic violence, relationship issues and so on, so it is difficult to deal with CSE as such' (Focus Group 2)

In terms of group work respondents identified both strengths and weaknesses. Some concern was expressed:

'Group work? You have to be careful - we have some have been quite low risk [on the CSE risk matrix] and then within weeks they are high risk because of the association!' (Focus Group 1)

A more mainstream approach was favoured by some, drawing on youth work:

'They are best in groups with 'normal' youths - learning about healthy relationships and so on - [otherwise] it makes it like they are the issue and they're not' (Focus Group 1)

A worker, who had a focus on supporting parents, saw the value of family-based approaches:

'Family therapy is a.....massive need.....if they all want to go for it then definitely' (Focus Group 1)

In summary, in terms of therapeutic approaches the focus of the respondents was similar to that when support was discussed: the professionals emphasised the need for relationship-based work, flexible approaches and being person-centred, whilst recognising the specific impact of CSE on the young people. Group work could be useful but required careful thought and planning. 


\section{Multi-disciplinary working}

All the workers mentioned that multi-disciplinary working was essential to addressing CSE. The need for multi-disciplinary working was reflected upon as follows:

'What is required is holistic, all the agencies together and with the statutory organisations working with the third sector' (Health professional)

Another, local authority-based worker mentioned, 'that we often utilise the third sector' (CSE social worker). A further respondent added that:

'There are a range of different, relevant professionals - health, GPs and sexual health professionals, for example - so it is about signposting to the services the young person correctly' (CSE co-ordinator)

In the specialist multi-disciplinary teams, which made up the focus groups, it was argued that different professionals have contrasting roles: for example, one of teams argued that the social workers, with statutory powers, played a more interventionist, controlling role, clearing the way for project workers to undertake the more supportive work:

'You [as a social worker] have broken down their relationship [with the perpetrator]. The Social Worker is seen as the 'bad one' and the young people are often resistant. But the support workers then get the young person on board. With the social worker the trust is lost and the support workers get more trust' (Focus Group 1)

The overwhelmingly consensus on multi-disciplinary approaches is summarised by the following response:

'They key is everyone working together - that is where it works the best' (CSE project worker)

\section{What works?}

All the professionals could give an example of generating positive outcomes with young people: again multi-disciplinary working was seen as the key. The example 
below, which is worthy of outlining in some detail, is illustrative of successful intervention:

'Our social worker worked with someone for the past 18 months or so - she was a young [European] girl. She experienced CSE, was missing from home, and found all over the country. The worker undertook work with her, but it was very up and down....... We felt the parents couldn't safeguard her, so she became a child 'looked after'. Since then she has been looked after she had disclosed, there was some very good work the police have been very good interviewing her supporting her with very positive policing ....... She has a long term placement and the outcome is that she is happy and safe, she is doing marvellously well with her new carers. She is fantastic at school she did have to move school, which you don't like to do, but she felt the other kids knew her business and she really desperately needed a fresh start. She is active in groups, and wants to be [a professional]. A brilliant piece of work by everyone, she had fantastic support' (Focus Group 1)

Here we see an example of multi-disciplinary working in action, providing positive outcomes for a young person.

\section{Challenges and issues}

Whilst success stories, such as that provided above, were frequently reported there were also many barriers and challenges in this complex work. For example, one respondent reported feeling, 'let down by the police and courts' (CSE project worker) in a particular case, when a case was not taken through the court process.

Many respondents felt that whilst they could offer support and intervention the provision of therapeutic help was a serious shortfall:

'..... the only need we can't meet as a team is the therapeutic and mental health needs. That is where we struggle, everything else we can do.' (Focus Group 1)

Another reported that they could meet most of the needs of young people 'but therapeutic - no, I'm afraid not!' (Focus Group 2) 
There were also issues with continuity of support and the transition to adulthood:

'We can only see them until they are 18 . There is no specialist therapeutic service really, nothing really' (Focus Group 1)

There were also concerns about thresholds and the level of the challenges faced by individuals before services were triggered:

'The (mental health) Crisis Team are good ... but things have to be really bad before they get involved. It is not fair to the young people that you need a crisis before you get a service' (CSE project worker)

A parents-focused worker stated that:

'The parents would speak to myself or speak to the social worker if they felt stuck and the parents know to go to GP or CAMHS [Community and

Adolescent Mental Health Services] and we advocate for them, if they are not being heard. They often feel that they are not being heard' (Focus Group 1)

A recurrent theme in terms of challenges related to the transition from children to adult services, often triggered by the service users $18^{\text {th }}$ birthday. Frustration was experienced by a range of respondents in relation to this:

'Just as they have turned 18 it doesn't mean that everything should stop'. (Health professional)

'You know the young person needs more support and if you had a little bit longer it would have made the all difference' (Focus Group 2)

'People may need the service up to 25. As they get older we can support them living more independently, they can be more vulnerable if they are living on their own' (Focus Group 1)

Whilst all the respondents presented as enthusiastic and positive, they were aware of when multi-disciplinary work failed and the difficulties in the transition between child and adult services. The struggle to access mental health support was a recurrent frustration. 


\section{Discussion}

This article has explored the views and experiences, the 'practice knowledge', of specialist professionals in relation to the support and therapeutic needs of children and young people who have experienced CSE. The data suggests that professionals are confident about their ability to build trusting relationships, often based on awareness raising and practical help. This is a conscious strategy by professionals to counteract the grooming undertaken by perpetrators, who deliberately undermine the trust of the young people in caring adults in their lives. Once this trust is established steps can be taken to safeguard the young people. Safeguarding is embedded in effective multi-disciplinary work, which is demonstrated by the data presented above. The respondents favour a flexible approach rather than one wedded to a particular model, a finding consistent with the work of Warrington et al:

'the quality of the therapeutic relationship emerges as more significant than the particular model or approach adopted' (2017, p.10)

It also emerges from the interviews that whereas the professionals feel able to offer support and effective multi-disciplinary interventions, there are still many challenges and barriers in offering effective longer-term, mental health interventions. There is, the respondents suggest, a serious challenge for public mental health resulting from the shortfall in service provision for young people's mental health. The shortfall in therapeutic support is embedded in the official approach taken to tackling CSE which is based in the 4Ps - prepare, protect, prevent and pursue (see https://www.csepoliceandprevention.org.uk/, for example). This dominant approach reflects the lack of emphasis on support and therapy, which needs to be addressed if the situation is to be improved in the future.

A model emerges from this study as follows: the professional builds a relationship based on trust, the young person can then be safeguarded, and once this has been achieved the therapeutic work can commence. It is at this latter stage where the current shortfall in mental health provision can be perceived. 


\section{Conclusion}

The professionals interviewed for this article have argued for relationship-based practice founded on trust and embedded in multi-professional responses. They are frustrated by the lack of joined-up approaches between child and adult services, symbolised by the $18^{\text {th }}$ birthday of the young person. The findings here are consistent with those of Hickle and Hallett who argue for a 'multi-systemic approach' that promotes:

'self-efficacy, empowerment, healthy decision-making skills and .... provided to CSE victims in the context of trusting relationships that pave the way for continued contact and help-seeking behaviours' (Hickle and Hallett, 2016, p. 305).

The professionals value their relationships with the young people, but perceive that there is a lack of specialised, therapeutic services. To address the shortfall will require policy and funding shifts: this is the central challenge for the future of public mental health provision for CSE-experienced young people.

\section{References}

Beckett, H., Brodie, I., Factor, F., Melrose, M., Pearce, J., Pitts, J., Shuker, L. and Warrington, C., (2013) " It's wrong - but you get used to it": a qualitative study of gang-associated sexual violence towards, and exploitation of, young people in England. University of Bedfordshire.

Davis, A., (2002). 'Don't Let Nobody Bother Yo' Principle': The Sexual Economy of American Slavery. Sister circle: Black women and work, pp.103-27.

Department for Education (2017) Child sexual exploitation: Definition and a guide for practitioners, local leaders and decision makers working to protect children from child sexual exploitation. London: Department for Education

Department of Health (2000) Safeguarding Children involved in Child Prostitution, London: Department of Health 
Eraut, M., 2002. Developing professional knowledge and competence. London: Routledge.

Girl A (2013) Girl A: the truth about the Rochdale sex ring by the victim who stopped them. London: Edbury Press

Hallett, S., (2017). Making sense of child sexual exploitation: exchange, abuse and young people. Bristol: Policy Press.

Harris, J. and Roker, D. with Shuker, L., Brodie, I., D'Arcy, K., Dhaliwal, S. and Pearce, J (2017) Evaluation of the Alexi Project 'Hub and Spoke' programme of CSE service development: Final Report November 2017. Luton: University of Bedfordshire.

Hickle, K. and Hallett, S., 2016. Mitigating harm: Considering harm reduction principles in work with sexually exploited young people. Children \& Society, 30(4), pp.302-313.

Hill, P. (2016) Multi-agency working to safeguard children from child sexual exploitation in Frost and Robinson (eds) Developing multidisciplinary teamwork for integrated children's services. Maidenhead: McGraw Hill

Hossain, M., Zimmerman, C., Abas, M., Light, M. and Watts, C., (2010). The relationship of trauma to mental disorders among trafficked and sexually exploited girls and women. American Journal of Public Health, 100(12), pp.2442-2449.

Jago, S., Arocha, L., Brodie, I., Melrose, M., Pearce, J.J. and Warrington, C., (2011). What's going on to safeguard children and young people from sexual exploitation? How local partnerships respond to child sexual exploitation. University of Bedfordshire.

Jay, A. (2014). Independent Inquiry into Child Sexual Exploitation in Rotherham: 1997-2013. Rotherham: Rotherham Metropolitan Borough Council.

Lefevre, M., Hickle, K., Luckock, B. and Ruch, G. (2017). Building trust with children and young people at risk of child sexual exploitation: The professional challenge. British Journal of Social Work, 47(8), pp.2456-2473. 
Ofsted (2016) Time to Listen. London: Ofsted

Parton, N. (1984) The Politics of Child Abuse. London: Macmillan

Pearce, J. (2017) Preventing child sexual exploitation, in Dolan and Frost (eds) The Routledge Handbook of Global Child Welfare. London: Routledge

Sneddon, H. Wager, N. Allnock, D. (2016) Responding Sensitively to Survivors of Child Sexual Abuse. London: Victim Support

Warrington, C., Beckett, H., Ackerley, E., Allnock, D and Walker, M. (2017) Making noise: children's voices for positive change after sexual abuse. Luton: University of Bedfordshire / Office of Children's Commissioner.

https://www.csepoliceandprevention.org.uk/ 